\title{
Spontaneous recovery of Right Bundle Branch Block (RBBR) in Acute Anterior wall Myocardial Infarction with Bifascicular Block
}

\author{
${ }^{1}$ Dr Bala Ram Shrestha
}

'Th Sheninar Babu Rimyal

${ }^{3} D_{\text {r Ratria Raj Poldy }}$

\begin{abstract}
A case of Acute Anterior Wall Myocardial Infarction with Right Bundle Branch Block (RBHB) and Left Anterior Hemi Biock (LAHB) - Bifascicular Block had been observed to have undergone spontaneous recovery of RBBB and the plan for transvenous temporary pacemaker insertion was with held.
\end{abstract}

Keywords: Right Bundle Brarch Block (RBBB), Anterior wall Myocardial Infarction, Acute Myocardial infarction, Bifascieular Block, Left Anterior Hemi Block (LATiB)

\section{BIFASCICULAR BLOCK : LITERATURE REVTEW}

Bundle Branch Block occurs ju eight to thirteen percent of patients with Acite Myocardial Indarction (AMI) anc is mainly Associated with Anterior Hall All ' Norris et a1. ${ }^{2}$ found RBBB in sever percent of patients and Left Bunfide Branch receiving single blood supply from a branch of Left Arterior Descending Artery which is a slender discreze structure with a iong subendocardal situation, liable to more froupent involvenent in contrast wo the Left Bundie Brancr Terejving dual blond supply with short and diffuse colure."

In Anterior Wail AMI, RBBB oceuse in ien percent of patiente and Compete Heart Brock (CIIB) in five peresu of paijents. About wise in three patents wh Acute RBBB in Anterion Wall AlI develons CHB, "Wost of the Watients with CHB attu? Anterior Wall ABI
Eive history of Stokes Adam's attack and therefore pacing is necessaly 4 Lnfortunately the degree of myocardial damage sustainned in pationts with anterior wall AMI with CHB is severe and in spite of transvenous pacing, hospital mortality is sixty to seventy porcent and fifty percent of survivors die within next. vara.t.

Bifiecicular Block ether in the form of RBFB and IAAHF or RBBP and LPEIB (Left Puscrion Hemi B]ocks ocurs in eight to thirteen percent of patients with AMI. LAHB and $R A B B$ is more common combination ocouring in thres to four percent of patients win AMI as both as these structures are supplied by Left Anterior Tescending artery. As an isolated finding IAHB alone does not increase hospital rortality When found with RPBB it is called Bifascicular block and in such condition chanee of going innto CHI3 is hagh

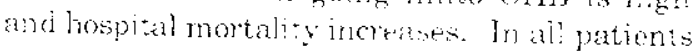

MBES ("IT, Gonior Henisc Ontier. Wept of Med. TLTH

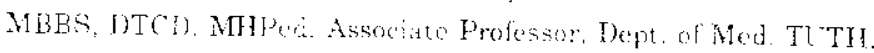

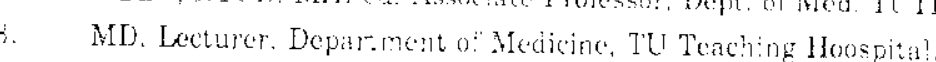


Wall AMI with new RBHB,

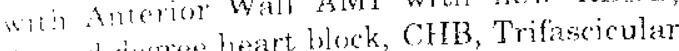

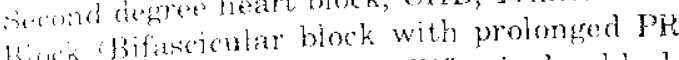

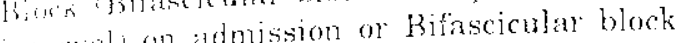
wioned $P R$ intervali on admission or

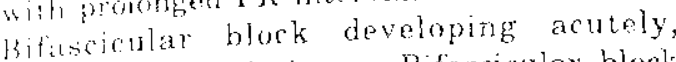
l'umporary admission or Bifascicular block 3uvelopince acutely, temporary pacing is whicated. ${ }^{7}$ pacing in new RBBB with $A M I$ has in recomnended in many cardiac centres. It Was been found that AMI with RBBR has higl chance of going into $\mathrm{CHB}$ mainly in anterior wa!l AML and in such cases prophylartic pacing reduces mortalty. All prtients with Anterior Wall A.MJ with CHB should undergo fermanent pacing whether CHB resolves or This has significantly reduced sudden doith atter hospital discharge 2,7

In a study of one hundred cases of $\mathrm{AM}$ by Dr. A. Saymi, thirteen percent patients wh AMl had RBBB four RBBB on admission, Gu RBBB on the first day later to adrnission iand fin RBBB appedred on the sacond day) "lekere are mo significant differences of RBBis in antorior wall and 6 percetit with anterior wall $A M I$ and these percent wht inferior wall $A M I$. Sue percerte of patients developed CIHB (six Mrente with anterior wall AMs and thes wererte with infertor wall AMl. Out of the six wercost we patients with anterior wall $A M 1$ ander then who hed CIB, three powent had

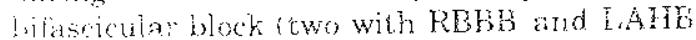

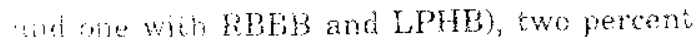

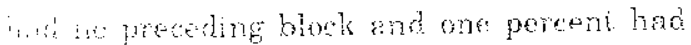

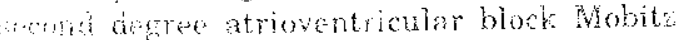

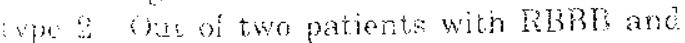
A Th onge inte hH, one reverted to sinus Ayine dre injection of Acropine but one

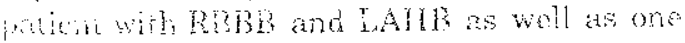

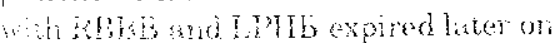

\section{Whith?}

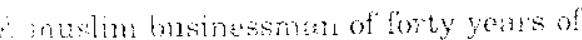

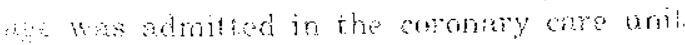

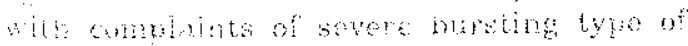

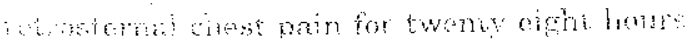

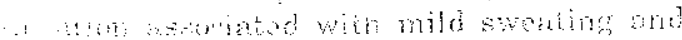

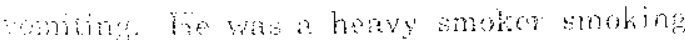

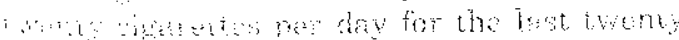

years as well as a heavy alcoholic

On examiration, he was restless and in agrony with pulse rate of 120 per minute, regular with arterial wall thickening. He was febrile with temperature of $102 \mathrm{~F}$. Pallor, icterus, clubbing, cyanosis, oedema, lymphadenopathy were absent. Cardiovascular examination revealed tachycardia with normal first and second heart sounds without third heart sound or murmer or pericardial rub. Respiratory system examination revealed notmal vesicular brerathsound without basal crackles. Abdomen and nervous system examination were wrimemarkable

The laboratory juvestigation revealed Haemorlobin $16 \mathrm{gm} \%$. Totel leucocyte count $12,700 / \mathrm{cmm}$ with $72 \%$ polymorphs, $22 \%$ lymphocytes and $6 \%$ eosinophils, random blood sugat $5 \mathrm{mmol} / 1$, urea $3.8 \mathrm{mmol} / \mathrm{CPK}$ $453(15-125) \mathrm{IU} / 1$, SGOT $136(5-40) \mathrm{U} / 1$, LI)H $804(80-320)$ IU/1 and after twenty four hours CPK 534 IU/1, SGOT $144 \mathrm{U} / \mathrm{T}$ and TDH 805 IU $/ 1$.

Photo No. 1 First electrocardiograph (FCG) recorded in Emergency deperment, showing Left Axis Deviation, tachycadia (QRS rabe 120/rninh, regular rhythm with deep ge wayes in $\mathrm{Vi}, \mathrm{V}, \mathrm{V}, \mathrm{and} \mathrm{ST}$ elewion in $\mathrm{V} 2, \mathrm{~V}, \mathrm{VA}, \mathrm{VS}$ and $v_{6}$

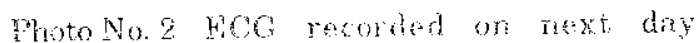
Showing RBBE and Abmomal Left Axis

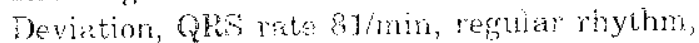
des, fo wave in 71,72 , v3 and ST eletetion in

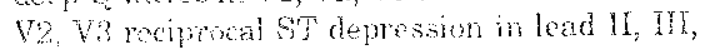

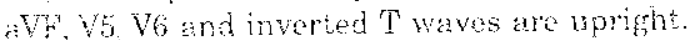

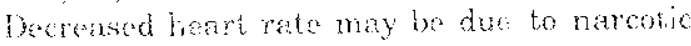
andigesic, sochtion ard Atenolol (25me two domest

phote Ne.3 ECa joended sir homs alte?

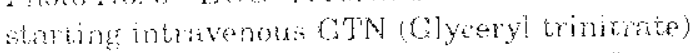

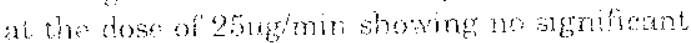

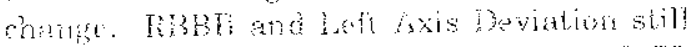

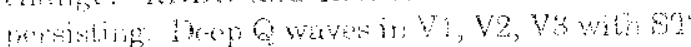

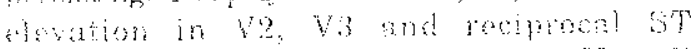

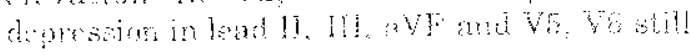
arm 
Photo So. 4 Fole reorded after forty eight hours of intravenous indisson of GTN showing inverted T'wase in V1 has iocome umbeht. No other significant changes. PBBBb and loft axis deviation still persisting.

Photo $\mathrm{Xu} 5 \mathrm{~F}$ CG recorded on eicthth day of admission and ninth day of AMT showing rocovery of RBBB. I eff avis deviation is stil] present. Q waves in $V_{1}, V_{2}, V_{3}$ and $V A$ and inverted T waves in V5, V6. II, III, aVF.

Photo No.6 ECG recurded on fourteenth day of admission showing absence of RBBB,Q

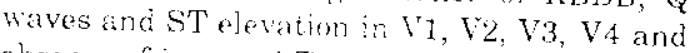
absence of inverted $T$ wates in $V_{4}, V 5$, V6 and II, III, aVF.

\section{DISCUSSTON}

Patient attended TU Teaching Hospital Emergoncy department twenty eight hours after th: arset of severe chest pain. Initially the patient had fertures of Acute Myocardial infarction (Antero-septa! infarction) with abnormal left axis deviation and tachycardia The next morning iforty hours of AMI), RBBB was noticed in ECG. His QRS rate was 107 min tachycardia! despite adequate doste of narcotic analgosic, sedation overnjght and Atenolol two doses of $25 \mathrm{~m}$ c! which was given due to taciycardia on the day of admission and next morning. There was to bifascicular biock on the day of admission. Although Aienolol car increase the degree of atrio-bentricular block it nas not been reported to indue $\mathrm{RBBB}$. The RBBB did not disappear even after stopping Atenolol for seven days in this patients.

\section{REFERENCES}

1. Niretz S.; Significances of Bunde Brator

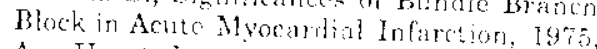
Ani. Hoart. I. an: $434-44$

2. Nomis r.M., Bundie Brench block in Acote Myorardial Infarction, 1970 , Am. Heam. J $74: 726-733$

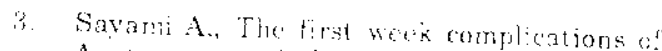
Acute myocardial infarotion. Institute of
As the pationt bas continuousiy complainjug severe ches pair so Glyceryl trinitrate GJN infusion was stajted or the second day of admision aid comtinued for forty eight hours but no apparent ECG changes including RBBb was noticed. He did not develop complete heart block during his fourteon days hospital stay and his heart rate was alwars in upper limit faround ninety beats per minute) and initially had tachycardia mostly likely due to severe chest pain of AMI. On the eighth day of admission, Spontaneou recovery of RBBSi took place. This cyont was preceded by change of inverted Thexe in VI into mprigh: "T wave. "This may be the sign of recovering $R B R B$. It was noticed two days before recovery of $R B B B$. On the fourteenth day of admission, RBBB was absent but inverted $T$ waves in $Y 5$, V6 IT, III, a Y $\mathrm{F}$ were stili present despite oral Isosorbide mononitrate 20me ThS dosige.

'Though new RBBF in anterior wall AVIl is considered to be warning sign of ensuing CHB and prophylacric pacing is said to be indicated, spontaneous recuvery is possible. Even if CIB appoars. it miy revert back to sinds riythm simply with injection of Atropine 3 Hence careful observation for appearance of CHB may be enough in hospital.s without pacing facilicy and referral centres with pacing facility being quite far away. It should he remembered that very high mortality rate sixty to seventy percenti in Anterior Wal Mrocardial Infarction wits CHB can occur cren in patients who are paced. Patient may be refered to utarest possible referral centre with Isuprealine drip as an alternative.

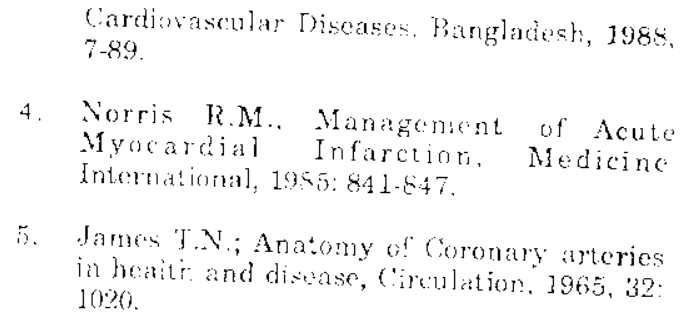


Finacid and Botti; Significance of isolated Wert Anterior Hemi Black in Acute

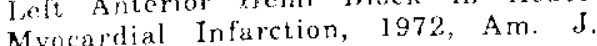
Cardicl., $30: 797$.

7. Slomaty G. and Itunt D.; Maragement of Myocardial Infarction - Recent advances in cordiology: Churchill livingstone
Publication, Fidinghurg, 1981, 29.71.

8. Patney; Management of heart block in Acute Myocardial Infaretion by trarsvenous paciog, Irdian Heari J. 25; 111 120. 